\title{
El directo con señal móvil en programas informativos de televisión generalista. El caso de Espejo Público de Antena 3
}

\section{Live remote mobile signal broadcasting on generalist television news programmes. The case of Espejo Público on Antena 3}

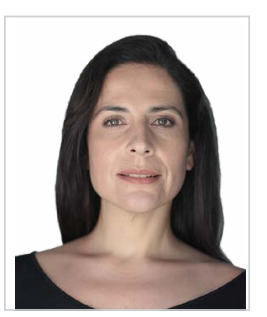

Saida Santana Mahmut. Doctora (Universidad Rey Juan Carlos), licenciada en Periodismo, Ciencias de la Información (UCM), Máster en Artes Escénicas (URJC), Máster en coaching (UCJC). Docente de la Universidad Antonio de Nebrija y New York Film Academy (Los Ángeles). Presentadora del programa 40 años de TVE en Canarias y presentadora y guionista de Ida y vuelta. Coordinadora de guion en TVE con Juan Ramón Lucas en el programa de entrevistas En noches como ésta. Guionista de El Terrat para La Sexta, La Ardilla, Literal PC, TVE 2, Garza Producciones en Los Ángeles y Telemundo (NBC) en Miami en la actualidad. En prensa ha colaborado en las Revistas Pshycologies, Aprendelo.com, Azure.com y I am not your boring newspaper de Miami en la actualidad.

Universidad Nebrija, España

ssantana@nebrija.es

ORCID: 0000-0002-5248-337X

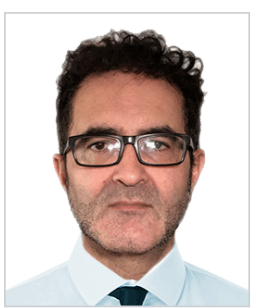

Vicente Sanz de León. Doctor en Comunicación Audiovisual y Máster en Tecnologías Digitales Interactivas por la Facultad de Ciencias de la Información (UCM). Profesor de Realización Audiovisual: Televisión, en el en el Doble Grado de Periodismo y Comunicación Audiovisual en la Universidad Rey Juan Carlos. Profesor de Tecnologías Audiovisuales: Cámara y Sonido en el Grado de Comunicación Audiovisual en la URJC. Coordinador del Aula Productora Audiovisual de la Facultad de Ciencias de la Comunicación y Coordinador de la asignatura de Tecnologías Audiovisuales: Edición, de la URJC. Su labor investigadora es en el área de la Comunicación Audiovisual, con varias investigaciones y publicaciones especializadas en la Formación y las Nuevas Tecnologías. Ha trabajado como operador de cámara para diversas productoras para programas de Atresmedia, TVE y Movistar entre otros.

Universidad Rey Juan Carlos, España

vicente.sanz.deleon@urjc.es

ORCID: 0000-0001-6875-4130

Recibido: 15/06/2021 - Aceptado: 20/10/2021 - En edición: 14/12/2021 - Publicado: 01/01/2022

Received: 15/06/2021 - Accepted: 20/10/2021 - Early access: 14/12/2021 - Published: 01/01/2022

\section{Resumen:}

Este artículo analiza formal y técnicamente las conexiones en directo de la televisión mediante envío de señal móvil, dado que es la cualidad que garantizará el futuro de la televisión. Metodología: utilizando técnicas cuantitativas y cualitativas se han analizado las conexiones en directo a lo largo de una semana del magacín Espejo Público, estableciendo una primera variable en torno a su duración. Un segundo bloque se centra en la narrativa audiovisual y características formales de su emisión. Los autores han realizado entrevistas en profundidad a la directora y a la productora del programa. Resultados y Conclusiones:

\section{Abstract:}

This article aims to formally and technically analyse live remote television broadcasts using a mobile signal, since it is an aspect that we believe will ensure the future viability of television. Methodology: using quantitative and qualitative techniques, we have analysed the live remote connections over a week's Espejo Público newsmagazine $T V$ programs, identifying an initial variable regarding their duration. A second variable focuses on the audio-visual narrative and its formal characteristics when broadcasting. We have conducted in-depth interviews with the program's director and producer. Results and

Cómo citar este artículo:

Santana Mahmut, S. y Sanz de León, V. (2022). El directo con señal móvil en programas informativos de televisión generalista. El caso de Espejo Público de Antena 3. Doxa Comunicación, 34, pp. 55-77.

https://doi.org/10.31921/doxacom.n34a898 
el uso de la señal móvil en el directo en televisión se ha implementado progresivamente a lo largo de los últimos 10 años, agilizando su producción, ampliando sus ubicaciones, sus movimientos y sus desplazamientos, asumiendo y siendo incorporado a sus sistemas de producción por la mayor parte de las televisiones, especialmente en los magacines informativos de actualidad. Tras el análisis de sus conexiones, desde el punto de vista informativo, periodístico y audiovisual, se concluye que la mayoría de las conexiones en directo en Espejo Público cumplen con la esencia del más puro directo televisivo, por su valor informativo directo y por ser "directos sincrónicos".

\section{Palabras clave:}

Directo televisivo; televisión; señal móvil; magacín; Espejo Público. conclusions: The use of the mobile live remote connections has been progressively adopted over the past ten years, streamlining production, expanding locations, ranging further afield and with most television channels including it in their production systems, particularly in the case of current affairs news programs. Following an analysis of live remote connections, from an informative, journalistic and audio-visual standpoint, we conclude that most of the live connections that take place on Espejo Público comply with the essence of live television, they provide live reporting of the news and are in 'real-time.'

Keywords:

Live television; TV; mobile signal; newsmagazine; Espejo Público.

\section{Introducción}

La producción televisiva ha ido evolucionando y ampliando sus posibilidades a medida que la tecnología ha facilitado la infraestructura necesaria para solucionar barreras que hasta hace poco eran casi impensables de superar. Si el valor del directo siempre ha sido uno de los pilares de la televisión, en la actualidad cobra especial importancia, dada la gran cantidad de contenidos a disposición del público en un elevado número de plataformas. El consumo se ha fragmentado y el espectador, excepto en ocasiones especiales, ya no es cautivo de la programación y de los horarios de la parrilla televisiva, pudiendo elegir el modo de consumo de los contenidos ofertados, tanto en horario como en pantalla y plataforma. Por ello, cierta programación, como los magacines, hacen del directo una característica que muestra al espectador que el periodista está en la calle, donde sucede la noticia. Según Araceli Infante Castellanos, directora del programa Espejo Público de la cadena de televisión Antena 3, en una entrevista en profundidad realizada por los autores de este artículo, comenta que hoy en día no solo hay que cumplir con la esencia misma del directo, que es estar en los sitios donde pasan cosas, sino "establecer determinada relación con el espectador para que entienda que estamos en la calle. Que no nos quedamos solamente en el plató” (Santana y Sanz, 2021, p. 1).

El directo ha evolucionado gracias a la tecnología y esto le ha llevado a una evolución también en la narrativa. La innovación requiere un enfoque multidisciplinario que combina métodos cualitativos y cuantitativos para conectar con las necesidades de los usuarios (de Lara et al., 2015).

Tradicionalmente la infraestructura necesaria para su producción ha sido costosa y ha requerido de una logística compleja: un gran despliegue de medios técnicos, equipo, presupuestos y transporte, entre otros. Reducir esta complejidad ha sido uno de los retos de las nuevas tecnologías que perseguían implantar un sistema digital en el que se pudiera enviar una señal de alta calidad directamente a los centros de control de los diferentes canales de televisión. Para Infante, "cuando la tecnología funciona bien te lo da casi todo y ahí entra el criterio del periodista para elegir lo que retransmite y lo que no, lo que prioriza y lo que no" (Santana y Sanz, 2021, p. 1). La tecnología ha mejorado bastante, nos ha permitido llegar mucho más lejos y contactar con más gente.

Desde hace 10 años, gracias a los sistemas de comunicación móvil, se ha logrado reducir el despliegue logístico, se han rebajado costes, se ha reducido el tamaño de los equipos técnicos y también el equipo humano, comparado con el envío de señal por sa- 
télite y radiofrecuencia. Esta última tecnología se materializa en ligeros dispositivos codificadores de enlace 3G, 4G y 5G, que se pueden transportar en una pequeña mochila. Son dispositivos ligeros, de $1 \mathrm{~kg}$ o menos, que permiten el envío de señales en H264 y H265. Mediante un conector BNC y salida SDI, la cámara se conecta al dispositivo y este envía toda la señal de audio y video al centro de control. Estos dispositivos han agilizado el proceso de producción sin afectar a la calidad de la emisión. Las tecnologías de los satélites no han desaparecido y de hecho "son cada vez más diversas y omnipresentes", (Maniewicz, 2019) pero en el caso de los directos de televisión ha pasado a usarse solo en eventos concretos, priorizándose el uso de conexiones móviles que agilizan los procesos de producción.

Los proyectos televisivos basados en sistemas de comunicación móvil permiten la instalación y la emisión desde el propio set en interiores, hasta prácticamente cualquier lugar en exteriores, algo que con los tradicionales y pesados equipos DSNG -Digital Satellite News Gathering- o unidades móviles, no siempre era posible. Además, estas unidades móviles tienen una duración óptima solo de 10 años.

Un gran caso significativo es la reducción de la infraestructura en la transmisión de competiciones de carreras, como el ciclismo y los maratones, donde muchas veces es necesaria la intervención de un helicóptero para el envío de la señal. Actualmente la producción en directo sobre IP permite el envío directo a través de un equipo de la cámara autónoma. Los sistemas a su vez evolucionan y se superan a sí mismos. Una de las empresas de transmisión de vídeo basadas en IP llamada LiveU que usa su tecnología patentada de igual nombre, ha sacado un último modelo LiveU800 HEVC que provee cobertura multicámara en una sola unidad. Este sistema se usó por primera vez en la Copa de Polo Cartier Queen's cup 2020 en agosto de 2020 en un evento cubierto por 4 cámaras cuya señal era enviada desde el parque de Windsor, Reino Unido, al estudio de producción en Sudáfrica de la cadena Polocam.tv. (LiveU, 2020). Como ocurre con otras marcas, comúnmente se llama a estos dispositivos por el nombre de alguna marca representativa, como es el caso de LiveU.

Las posibilidades en los directos de televisión a través del estudio, capacidades y evolución de los sistemas 3G, 4G y la potencial $5 G$, permiten poner en marcha nuevos y eficaces desafíos en el panorama televisivo.

Las ventajas del directo con envío de imagen a través de señal móvil frente a la unidad móvil DSNG son varias: precio, tamaño, reducción de equipo, simplificación de recursos y movilidad del reportero y operador de cámara. El DSNG es más pesado y requiere de un aparcamiento y lugar de ubicación de la unidad y permisos. En los directos se necesitan además ubicaciones concretas en el centro de la noticia. Con DSNG se tiene que cablear y ese cable se lo puede llevar accidentalmente un coche y cortar la transmisión. Para Nuria Donate, productora del programa Espejo Público de la cadena de televisión Antena 3, entrevistada en profundidad por los autores de este artículo, una DSNG "es estática y llega hasta donde llega, y el periodista no puede meter el canutazo, pero un sistema de envío móvil como LiveU -empresa de transmisión de vídeo basada en IP con tecnología de igual nombre-permite que el cámara y reportero se muevan donde quieran y hagan una puesta en escena" (Santana y Sanz, 2021, p. 1). Este sistema permite inmediatez y movimiento de redactor y operador durante el directo. "Momentos tales como la salida de Iñaki Undangarín de la cárcel o la entrada de Luis Bárcenas, no podrían haberse seguido si no fuera por este sistema”, explica Nuria Donate (Santana y Sanz, 2021, p. 1).

El riesgo o desventaja que conlleva el envío por equipos de transmisión 4G portátiles en mochila, puede ser el pixelado de la imagen, fallo de cobertura en un sótano, por ejemplo, o un pequeño delay o retardo de plató al punto del directo. Estos problemas se 
daban más al comienzo del uso de equipos de mochila, cuando solo había 3G. En el caso de Espejo Público el primer uso de este tipo de envío se dio en el año 2011. El aspecto del delay, pixelado o fallo en la cobertura se verá completamente solventado con la implantación del 5G. Otro riesgo que entraña este sistema puede ocurrir cuando se trata de una noticia muy importante en un sitio complicado. "Puede suceder que todos los servicios de mochila estén alquilados si no se pide con tiempo" explica Donate (Santana y Sanz, 2021, p. 4).

Otra de sus ventajas es su mayor rentabilidad económica, no solo porque los precios han bajado, sino porque se puede usar un servicio de mochila para varias conexiones en el mismo día. En Espejo Público un único servicio se ha llegado a usar para 3 conexiones en directo, lo cual supone una alta amortización. Aunque hoy en día el satélite no resulta tan caro y los equipos han visto reducido su tamaño, es un proceso más lento. Se ha de pedir al departamento de Reservas, booking, las vías. Han de ser confirmadas o buscar otras si están ocupadas. Esa señal siempre va a ser más segura que una mochila, pero dependerá de la utilidad que tenga ese directo y el tipo de programa. Según la productora de Espejo Público, "si se quieren hacer 10 directos no se podría porque no te da tiempo con DSNG. Pero con LiveU sí se puede. Puedes empezar a las 9 en Madrid y acabar a las 12 en Toledo" (Santana y Sanz, 2021, p. 2).

\subsection{Grabación, captación y envío de señal en el directo de Espejo Público}

En Espejo Público, habitualmente, la escaleta puede ir variando a lo largo de la tarde y hasta primera hora del día siguiente y durante el propio programa. De no haber cambios, al día siguiente producción contacta con los operadores de cámara.

Confirmado el envío, el proceso de trabajo comienza con el redactor y operador de cámara yendo por su cuenta al lugar de la noticia. El equipo de producción llama al operador de cámara una hora antes de la emisión para comprobar la calidad de la recepción de la imagen y el sonido. La imagen y el sonido se pasan a control y se verifican para su salida a emisión. La planificación se hace con una hora de antelación para "tener un margen, lo que llaman "aire" por si hay un cambio en la escaleta sobre la marcha y si fallan dos skypes que se pueda subir ese tema en la escaleta”, argumenta Donate (Santana y Sanz, 2021, p. 4).

En los directos de Espejo Público el dinamismo se consigue porque se cuentan historias y esto se logra informando e implicando también al operador de cámara. Para la productora del programa, "producción, realización y dirección tienen que ir de la mano y al final eso se aprecia en la emisión, si hay buena conexión entre los tres núcleos” (Santana y Sanz, 2021, p. 3). En la citación se especifica: fecha, lugar, tema, necesidades, tipo de servicio, citación con la información de los programas y contacto.

Las necesidades técnicas dependen del tipo de programa o conexión que quiera hacerse. Generalmente hay que incluir: cámara, micro de corbata y micro de mano. También dos teléfonos, uno para la comunicación del periodista con plató y otro para coordinación con el operador de cámara. Otras veces se especifican otras necesidades y se añaden elementos al equipo, como antorchas o paneles led, pértiga para el micro, etc. 


\section{Imagen 1. Dispositivo de cámara y mochila de emisión}

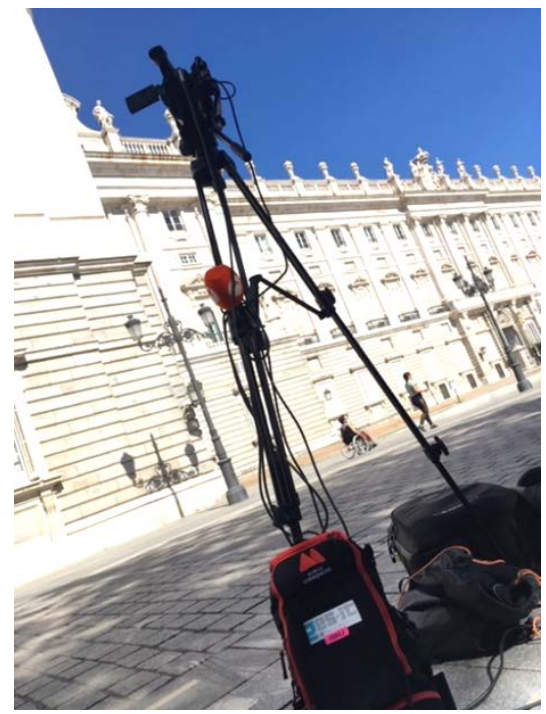

Fuente: elaboración propia

\subsection{Características del directo}

El avance tecnológico con el envío de señal móvil ha influido en la producción del directo y su agilización, pero también en la narrativa del discurso. En el primigenio periodismo televisivo, según Cebrián (1978, p. 217) el directo televisado permitía mostrar los hechos al mismo tiempo que estaban ocurriendo, creando un espacio nuevo al vincular espacios situados a distancia y en diversos lugares (Cebrián, 1978, p. 217), en los que se produce el hecho de interés periodístico. "La lógica informativa justifica el directo por la necesidad de estar presente durante el desarrollo de los acontecimientos de los que se pretende informar" (Mateos, 2013). Pero la realidad es que hoy en día muchas conexiones tienen un valor indirecto, en el que no ocurre nada porque ya es pasado. En esos casos, para Infante, "se trata de decir, "estoy aquí", porque estoy en la calle, en uno de los sitios cuyo nombre es noticia, con muchas comillas porque en el fondo nunca pasa nada” (Santana y Sanz, 2021, p. 1).

El directo sustituye el proceso de producción de una noticia y además exhibe su poder tecnológico, algo que atrae a los espectadores. Además, si la espectacularización es el uso de recursos de forma y de fondo que apelan a las emociones y a los sentimientos más que a la razón (Lozano, 2004), la importancia de la imagen y la mayor presencialidad del periodista son factores que contribuyen a ello en el directo.

El directo es usado por todos los programas, pero especialmente en los vinculados a la actualidad. Esto incluye informativos y, nuestro caso de estudio, el magacín matinal Espejo Público. De acuerdo con Marín (2006, p. 91), "al igual que el noticiario es el programa más representativo de la tipología de informativos, se puede decir que el magacín es el más representativo de los de entretenimiento". 
El directo traslada al espectador al lugar mismo de la noticia. "Es la primacía de la imagen, del directo y de la oralidad, las que dan a la televisión una lógica sensitiva, afectiva y emocional superior a las de la prensa escrita o la radio” (González Requena, 2009, p. 14). Antes se podía estar en el momento del suceso, se grababa y se daba algo. "Ahora se ha ampliado y se busca retransmitir en directo todo el momento independientemente de lo que dure”, añade la directora de Espejo Público (Santana y Sanz, 2021, p. 1).

Entendemos que el directo implica cuatro tiempos coincidentes: el del suceso, el de la elaboración narrativa, el de la difusión y el de la recepción-lectura (Cebrián, 1992) o tres, según la categorización de Concha Mateos (2013): el del acontecimiento, el de la enunciación del relato y el de la lectura. De acuerdo con Barroso (1996) el directo "tiene lugar cuando la señal de programa -discurso televisivo realizado- se transmite en simultaneidad a su captación” (p. 40).

La ubicación es otro elemento clave, "el redactor se encuentra en el lugar en el que ha sucedido, sucede o sucederá algo" (Mayoral et al. 2006, p. 250). El espacio ayudará a estructurar el discurso y las palabras se apoyan en lo que se ve.

De acuerdo con Marín (2006, p. 91). "al igual que el noticiario es el programa más representativo de la tipología de informativos, se puede decir que el magacín es el mas representativo de los de entretenimiento”. En el caso de Espejo Público, es un magacín informativo, que contiene géneros periodísticos como el debate, la tertulia, la mesa redonda, la entrevista, pero también la noticia y el reportaje. Al ser formatos diferentes es lógico que el tratamiento de la información y de la conexión en directo difiera de un informativo a un magacín. En este último adquiere una dimensión más espectacular, a pesar de su contenido igualmente informativo. Cabe decir que Espejo público empezó en 1996 como programa semanal de reportajes de actualidad y no fue hasta 2006 que se convirtió en magacín matinal de actualidad presentado por la periodista Susana Griso, de lunes a viernes de 8.55 a 13.30 horas.

\section{Objetivos}

El objetivo general de la investigación es extraer las características fundamentales de los directos realizados en el programa de Antena 3, Espejo Público.

Este objetivo se desglosa en los siguientes objetivos específicos:

- Conocer las características fundamentales: duración, desplazamiento del emisor, "última hora”, entrevista, tipo de plano, movimiento de cámara, composición y tipo de encuadre, naturaleza de la acción objeto del directo y categoría del directo según el escenario de la acción objeto del directo, emitidos a través de señal móvil en HD de los directos de hasta 1 minuto de duración, de entre 1 y 2 minutos, de entre 2 y 3 minutos, y de más de 3 minutos, emitidos a través de señal móvil en HD, durante la semana del 20 al 24 de julio de 2020, en el programa Espejo Público de Antena 3.

- Concluir pautas de comportamiento de las entradas en los directos en el magacín Espejo Público.

\section{Metodología}

La metodología utilizada en este artículo se compone de dos fases en las que los autores utilizan "tanto técnicas cuantitativas como cualitativas de análisis", en este caso de "documentos [...] sonoros o visuales" (De Miguel, 2005, p. 280), que corresponden a los programas de Espejo Público del 20 al 24 de julio de 2020. La primera fase del estudio es descriptiva y se aborda con la consulta de fuentes primarias con la técnica cualitativa de entrevista en profundidad, según describe De Miguel (2005, p. 253), también deno- 
minada "semiestandarizada", realizada por los autores del artículo a la actual directora del magacín Espejo Público, Araceli Infante Castellanos, y a su productora Nuria Donate; y la experiencia profesional de los autores con la tecnología de estudio en distintos medios de comunicación, así como fuentes secundarias: hemerográficas y bibliográficas. En cuanto al trabajo profesional de los autores se ha recurrido a la observación directa participante u observación global "en la que el investigador se integra en el medio ambiente del grupo estudiado e interviene en sus prácticas y rituales cotidianos” (De Miguel, 2005, p. 279).

La segunda fase del trabajo es empírica y consiste en el estudio pormenorizado de las conexiones en directo del 20 al 24 de julio del programa Espejo Público a través del análisis de contenido. Dicho análisis se ha elaborado siguiendo las pautas fundamentales del directo aludidas por Infante "que el reportero se pueda mover y enseñe donde está, en la medida de lo posible que sea exterior, que se vea donde está, que dé el cuadro lo más completo posible, que dé el mayor movimiento y que explique mejor la historia, y que incluya entrevista si es posible" (Santana y Sanz, 2021, p. 1):

Con esta idea se elaboró la siguiente ficha de análisis:

Duración de la conexión: minutos y segundos

Localización: interior o exterior

Tipología de emisor: corresponsal o reportero

Desplazamiento del emisor: sí o no

Contenido: temática de la noticia

Última hora: sí o no

Entrevista: sí o no

\section{Análisis de la imagen audiovisual:}

- Tipo de plano

- Movimiento de cámara

- Composición y tipo de encuadre

- Iluminación

- Sonido

Naturaleza de la acción objeto del directo. De acuerdo con la categorización de Concha Mateos (2013) se determinará si ocurre en el momento o si no ocurre en ese momento y "entonces el reportero se ocupa de lo ya ocurrido o de algo que provoque él" (p. 71).

Las variables son:

- Valor informativo directo: "asistimos a algo que está ocurriendo en ese momento" (p. 71).

- Valor informativo indirecto: "nada ocurre, salvo nuestra presencia como reporteros en el lugar. Puede que haya ocurrido antes (pp. 71-72)". 
Categoría del directo según el escenario de la acción objeto del directo según Concha Mateos (2013, p. 73) al que añadimos la categoría del "directo sincrónico", término ideado por los autores de este trabajo, en el que la acción de la noticia sigue transcurriendo mientras se informa sobre ella.

- Directo sincrónico. Cuando la acción ocurre en el momento de la captación y emisión de la noticia.

- Directo ilustrativo. Cuando la acción ya ocurrió, pero el lugar es ilustrativo. "Se acerca a un directo con sentido pleno: la acción destacable ya ha ocurrido, pero el estado del lugar es interesante informativamente en ese momento" (Mateos, 2013, p. 73).

- Directo perpetuo. Cuando hay relación con el espacio, pero es invariable. No ocurre nada en ese lugar que sea informativo (Mateos, 2013, pp. 73-74).

- Presente que se supone, imagina. Hay un presente ausente, que está pasando, pero no lo podemos ver (Mateos, 2013, p. 74).

- Directo arbitrario. Cuando se podría haber hecho igual desde otro sitio (Mateos, 2013, p. 74).

- Directo contrario. Cuando se está en un lugar, pero se habla de acciones ocurridas en otros lugares. (Mateos, 2013, p. 74).

- Colas: si el directo se acompaña de colas o no.

El programa Espejo Público ha sido elegido por ser un programa representativo de los magacines en España, longevo -emite desde el año 1996 en versión semanal y desde el 2006 en versión diaria- y por sus reconocimientos. Entre sus galardones está el Premio Nacional de la Fundación Alares, por el concilio de la vida personal, laboral y familiar y por la responsabilidad social; el Premio Ondas Nacional de Televisión a la Mejor Presentadora en 2010 (Premios Ondas, 2019), y el Premio Iris al mejor programa de actualidad en 2014 (Antena 3, 2020). La muestra escogida es de una semana lo que supone un total de 1.375 minutos de visionado, al tratarse de un programa diario de 08:55 a 13:30 horas.

\section{Discusión/Resultados}

En Espejo Público las pautas que se dan desde dirección en cuanto a contenido son básicas, "que el reportero transmita actualidad, que cuente bien la historia y desde todos los puntos de vista y que hablen con los invitados para que sepan que el tiempo es limitado y que han de ser concretos en el mensaje" (Santana y Sanz, 2021, p. 3). En cuanto a lenguaje audiovisual las pautas son: el reportero ha de moverse, tratar de localizarse en un exterior, que se vea dónde está, dar el cuadro más completo que se pueda, que dé mayor movimiento y que explique mejor la historia, se tiene que aprovechar que está ahí y no en otro sitio.

\subsection{Tipos de conexiones}

De la totalidad de conexiones en directo del programa Espejo Público, del 20 al 24 de julio, este trabajo se centra en aquellas en las que vemos a reportero y operador de cámara con pretensión narrativa de directo, más allá de que existan rótulos que indiquen que se trata de un directo o un "última hora". Nuestro análisis se enfoca en cómo la imagen y la noticia de esa realidad llega al público. Por tanto, se descartan las conexiones en las que no aparece el reportero, y los falsos directos explícitos en los que hay una 
entradilla que simula un directo, pero es seguida de un VTR editado. El objeto de estudio de este trabajo se centra en la conexión en directo, su narrativa, su puesta en escena y su significación en el discurso. En total analizamos 44 conexiones en directo, y descartamos 5 conexiones sin reportero y 8 falsos directos explícitos. Tampoco se analizan las videollamadas que entran por sistema convencional de videoconferencia a las que denominan Skype, (Santana y Sanz, 2021, p. 4), dado que no pertenecen al objeto de nuestro estudio.

Gráfico 1. Tipos de conexiones

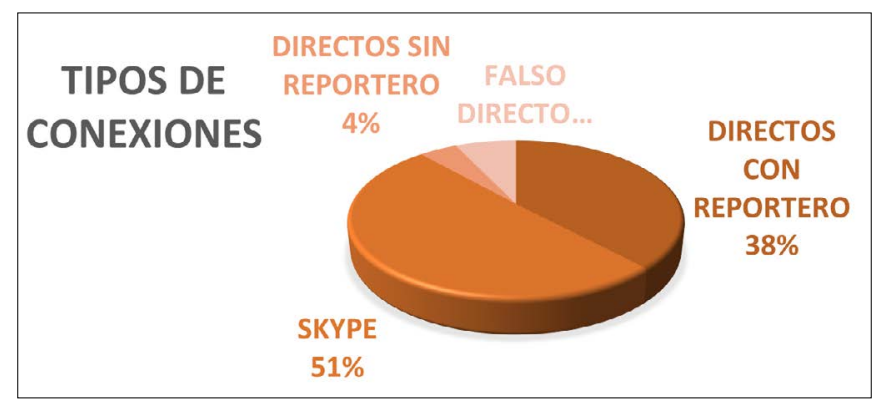

Fuente: elaboración propia

\subsection{Naturaleza de la acción objeto del directo}

La naturaleza de la acción de valor informativo directo cubre la mayoría de las conexiones, 39 veces. Estos directos cumplen perfectamente con lo señalado por Mateos (2013), ya que en estos casos el espectador presencia algo que está ocurriendo en ese mismo momento. "Ese es el valor esencial o más puro del directo" (p. 71). Por el contrario, los directos que tienen un valor informativo indirecto son solo 9 .

\section{Gráfico 2. Naturaleza de la acción}

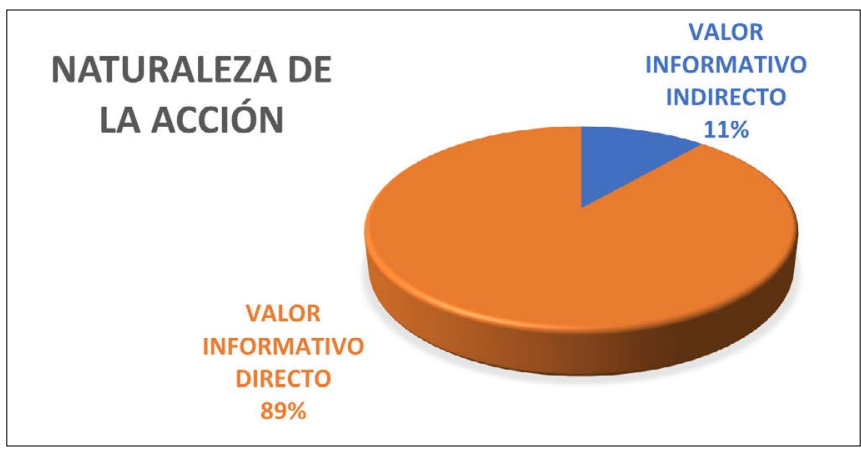

Fuente: elaboración propia 


\subsection{Categoría del directo según el escenario de la acción objeto del directo}

En esta categoría analizamos si el lugar donde tiene lugar la acción tiene relación o no con la noticia. El directo que más aparece es el "sincrónico", 18 conexiones, durante las cuales la acción ocurre en el momento mismo de la captación y emisión de la noticia y dura todo el tiempo de esta. Junto con el valor informativo directo, el “directo sincrónico" es el más puro directo. Algunos de los escenarios de las 18 conexiones son manifestaciones de los MIR, de los toreros, de los dueños de gimnasios o un polideportivo que recibe a ciudadanos para hacer PCR de urgencia, el interior de un colegio con la nueva señalética Covid para el comienzo del curso escolar, el interior de una farmacia en Andalucía donde se entregan mascarillas gratis a la tercera edad, los puestos de la Feria del libro, el lugar en Aguilar donde se está haciendo una excavación a tiempo real para buscar el cuerpo de Ángeles Zurera, o el interior de la T4 del aeropuerto Adolfo Suárez donde el reportero comprueba las nuevas pruebas de seguridad.

$\mathrm{Al}$ “directo sincrónico", le sigue la del presente que se supone, imagina, (Mateos, 2013, p. 71-72) en el que algo está pasando, pero no lo podemos ver, tal es el presente que ocurre dentro del hotel donde están los jugadores del Fuenlabrada confinados por el Covid, mientras que el reportero retransmite desde la fachada; o el presente que imaginamos con una menor agredida ingresada en el hospital de La Princesa de Madrid, mientras la reportera entrevista a su madre en el exterior. Siguiendo la categorización de Mateos (2013), continúan 8 directos ilustrativos y 2 perpetuos. En los ilustrativos la acción ya ha pasado pero el lugar sigue siendo noticia, tal es el caso del exterior de la cárcel de Santomera, en Murcia, de donde ha salido en libertad una parricida o el exterior de un comercio quemado en Torrox. Sin duda el reportero no captó el momento del incendio, pero el lugar calcinado y los restos de la tragedia ilustran lo ocurrido. En el directo perpetuo hay relación con el espacio, pero es invariable. Nada ocurre en el lugar que sea informativo, tal es el caso de la noticia sobre los rebrotes ocurridos tras una fiesta de fin de curso en Córdoba. En ese caso vemos a la reportera en el rellano exterior de un edificio que, aunque podría ser de la Seguridad, no tiene ningún elemento indicativo, con lo que nos llega como un edificio cualquiera en una calle cualquiera. El otro directo perpetuo es el referente a la noticia sobre la Cumbre de la Unión Europea y las subvenciones a España. En esta ocasión el corresponsal se encuentra en una calle urbana en Bruselas con el fondo de lo que podría ser un edificio emblemático de la UE pero que no llegamos a apreciar. Por ello consideramos que si el espectador no puede apreciar que está frente a un edificio de la UE, el lugar ya no es ilustrativo, sino perpetuo. Sólo uno es considerado contrario, el correspondiente a la conexión en Gandía, porque el directo se encuentra en un lugar y se refiere a acciones ocurridas en otros escenarios. 


\section{Gráfico 3. Categorías del Directo}

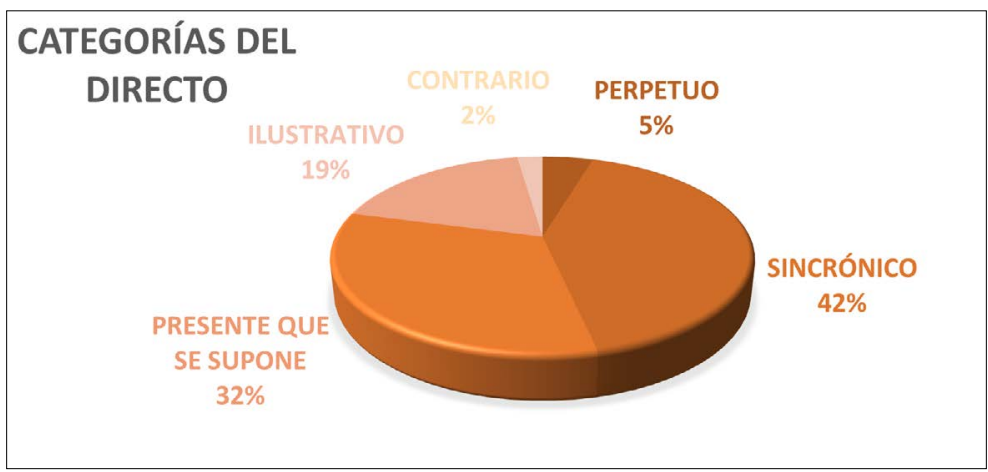

Fuente: elaboración propia

\subsection{Conexiones de última hora}

De los directos analizados hay un alto porcentaje de conexiones de "última hora"; 18 de 44 . Todas poseen un valor informativo directo según la naturaleza de la acción, excepto una: una noticia cuyo emisor es un corresponsal destacado en Bruselas en la fachada del parlamento europeo e informa sobre el acuerdo de las ayudas Covid concluido la madrugada anterior. En ese caso el valor informativo es indirecto ya que nada ocurre, salvo la presencia del corresponsal en el lugar, pero ocurrió antes.

Estos "última hora" se caracterizan por mantener la esencia primigenia del directo retransmitiendo desde el mismo lugar de los hechos, solo desde allí se puede narrar la noticia, bien sea, como mencionábamos anteriormente, una manifestación de los MIR frente a la sede de la Dirección General de Recursos Humanos del SERMAS, un pabellón donde se realizan PCR en Santa Pola, una protesta de gimnasios y centros deportivos contra su cierre, o una manifestación de toreros frente al Ministerio de Trabajo.

A pesar de contar con un valor informativo directo, la categoría del directo según el escenario de la acción es variada. Existen 8 directos que se dan en un presente que se supone, otros 8 que son "sincrónicos", y solo 1 perpetuo y 1 ilustrativo. La unión de un valor informativo directo y un "directo sincrónico" da la fórmula del directo por excelencia: asistimos a algo que está ocurriendo en ese mismo momento y además la acción ocurre en el momento de la captación y emisión de la noticia. Puesto que todos ellos tienen un valor directo no cabe la existencia de ningún directo arbitrario, aquel en el que nada ocurre salvo la presencia del reportero. 


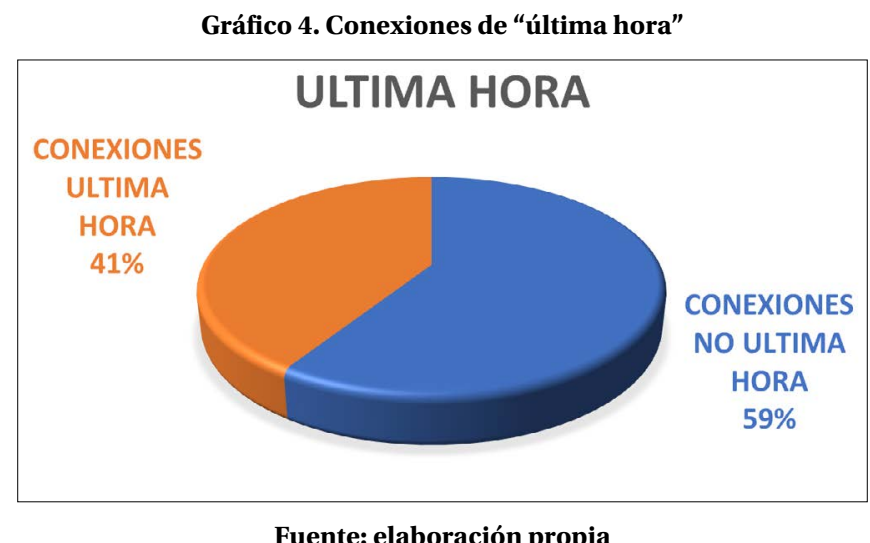

\subsection{Conexiones que incluyen entrevistas}

La entrevista en el directo aporta información de primera mano de algún protagonista de la noticia. Estas se dan en una alta proporción, 21 de 44. En cuanto a la dinámica de la entrevista en todos los casos es la misma. Se comienza con un plano americano o general con reportero y entrevistado para pasar en la respuesta a un plano medio del entrevistado. Entonces el cámara se coloca en la posición del reportero, dejándolo en escorzo o únicamente sacando su micro en cuadro. Cuando hay una nueva pregunta a veces se vuelve a reencuadrar para incorporar al reportero en el plano. Al finalizar la entrevista se reencuadra al reportero para su "salidilla", sacando de cuadro al entrevistado.

Gráfico 5. Conexiones que incluyen entrevistas

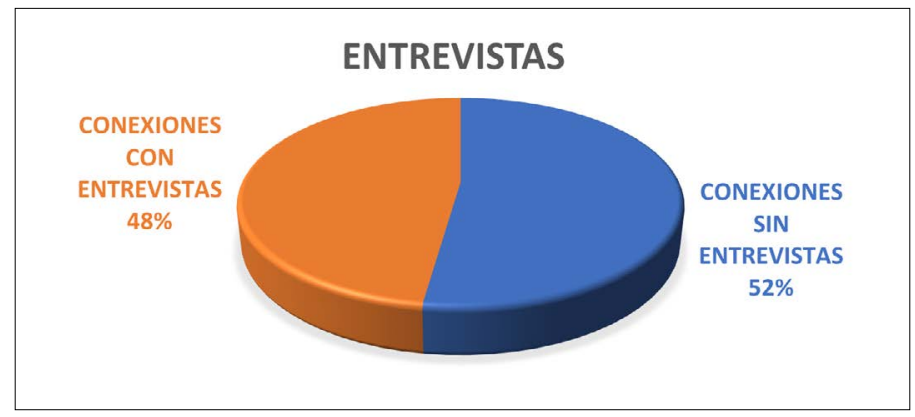

Fuente: elaboración propia 


\subsection{Desplazamiento del emisor}

El desplazamiento del reportero durante las conexiones es uno de los factores que apoyan la tesis de Araceli Infante sobre la importancia del programa de decir, "estoy aquí" (Santana y Sanz, 2021, p. 1), en la calle. Se busca retransmitir el momento, pero también estos desplazamientos ofrecen una espectacularidad que suple la ausencia de acción. En los 14 desplazamientos que hay en todos ellos la naturaleza de la acción objeto del directo es la de valor informativo directo. Del total de desplazamientos, la categoría del directo según el escenario de la acción objeto del directo, el “directo sincrónico” es el más común, 8. Le siguen el presente que se supone y el ilustrativo, 2 cada uno. En cambio, directo arbitrario y contrario solo hay 1 de cada uno.

Gráfico 6. Conexiones con o sin desplazamiento del emisor

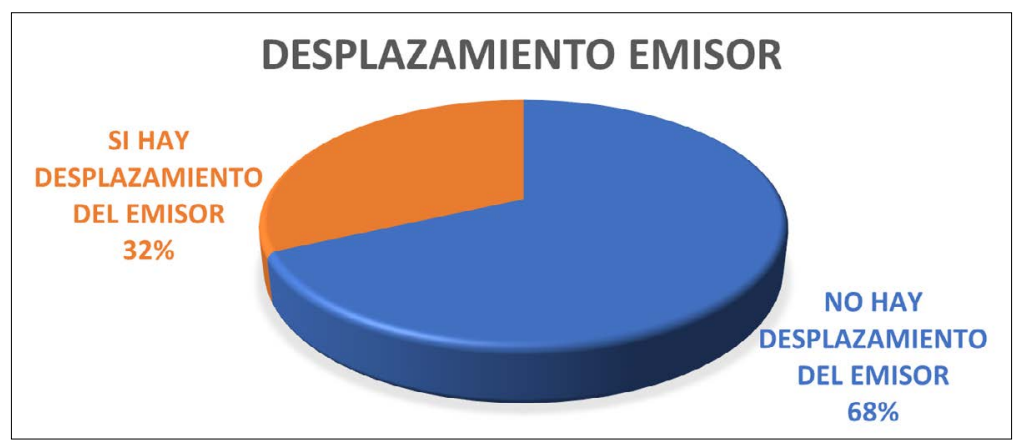

Fuente: elaboración propia

\subsection{Tipo de planos}

En la categorización de planos, la mayoría son Plano Americano (PA), 16; Plano Medio Largo (PML), 12; Plano Medio (PM), 13; y Plano General (PG), 3. Contamos la aparición de ese plano en el transcurso de una noticia y no el número de veces que se usa. El PG, que muestra al personaje principal y su entorno, apropiado cuando hay un movimiento significativo de la escena, aparece en 3 conexiones en directo. El PA que muestra al reportero desde las rodillas hasta la cabeza, es muy usado. Sin duda, el Plano Medio, en su tamaño normal y en su versión más amplia, ocupa casi la totalidad de los planos usados, un $57 \%$, y aparece en 25 directos.

El Plano Secuencia (PS) no lo hemos integrado dentro de la selección de tamaños de planos puesto que en su desarrollo va combinando distintos tamaños de plano y movimientos de cámara. En todo el estudio solo aparece un PS el día 21 de julio que dura 1 minuto y 45 segundos. Este PS posee las características del más puro directo con rasgos de espectacularidad. Comienza con un PA de la reportera en la entrada de un colegio. En travelling in, con la reportera caminando hacia atrás, entran a las instalaciones y se detienen donde espera el director del centro para ser entrevistado. Al finalizar la entrevista hay un travelling lateral de seguimiento para seguir a la reportera que se desplaza a su derecha y sacar de cuadro al director, hay un tilt down para sacar un detalle de la señalética del suelo, tilt up y continúa con un travelling de seguimiento y segundo tilt down a plano detalle para continuar con un travelling in con la reportera subiendo unas escaleras de espaldas. En este caso la angulación de la cámara es contrapicada por la 
posición del cámara más abajo. Continúa un travelling in siguiendo a la reportera entrando en un aula. Dentro, se hacen diversas panorámicas a derecha e izquierda, abajo y arriba que ilustran las medidas. En el tilt up se vuelve a componer el cuadro con el PA de la reportera para cerrar la conexión. Este ejemplo de puro directo lógicamente posee, según la naturaleza de la acción, un valor informativo directo, y según el escenario de la acción es un "directo sincrónico”. Este es uno de los ejemplos en los que no tienen cabida las colas pues todo está siendo mostrado a tiempo real.

Gráfico 7. Tipos de planos

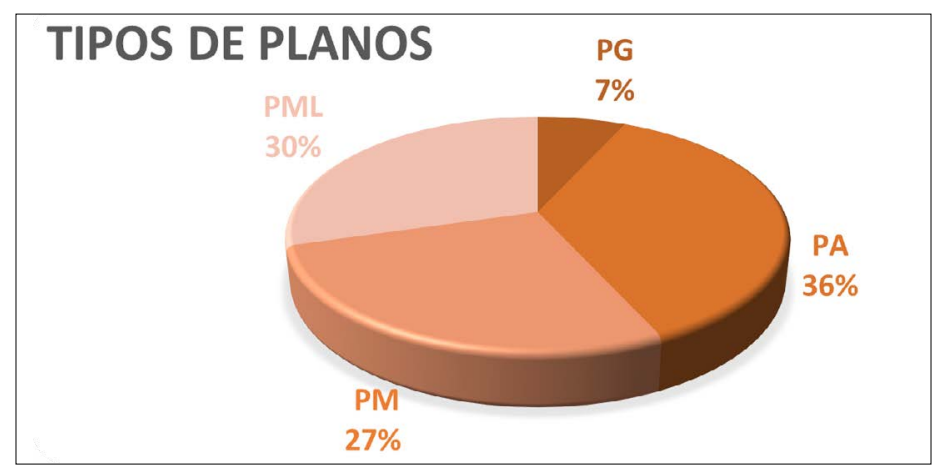

Fuente: elaboración propia

\subsection{Movimientos de cámara}

Según Millerson (2008), si no guiamos al ojo por la escena éste tenderá a vagar por la imagen. En este sentido los movimientos de cámara simulan lo que vería el ojo humano si estuviera en el lugar de los hechos.

De los 44 directos analizados solo 9 no cuentan con movimiento de cámara. Uno de ellos es en una carretera aledaña a la cárcel de Santomera, otro en la fachada del parlamento europeo, otro frente a la Comisaría de Eibar, otro en la fachada del Juzgado de Durango, y en el Hospital Aranau de Villanova. En todos estos casos la ubicación no permite movimiento y la importancia de la noticia está en mostrar ese lugar en particular donde están sucediendo o han sucedido los hechos. Las conexiones en directo con movimiento de cámara son mayoritarias, 35.

A continuación, mencionaremos los movimientos más comunes contabilizando una única vez su aparición en el directo y no sus sucesivas apariciones dentro del mismo. Entre los movimientos más comunes se encuentra el travelling: out, in, circular y de seguimiento lateral; panorámicas o paneos: a izquierda y derecha, arriba y abajo; y los movimientos ópticos: zoom in y zoom out.

De los 44 directos analizados el movimiento que aparece mayoritariamente es el travelling, donde cámara y soporte se mueven conjuntamente. En estos casos el soporte es el propio operador de cámara, cámara en mano. El travelling mayoritario es el travelling out, aparece en 24 conexiones. El travelling in en 8, el travelling lateral de seguimiento en 7 , y el circular en 2 . En cuanto a paneos, en los que la cámara se mueve sobre un soporte que permanece fijo, a derecha e izquierda aparecen en 27 conexiones, mientras que paneos arriba y abajo, en 4 . El zoom in aparece en 9 conexiones y zoom out en 10. 
Las tipologías de travelling suelen combinarse entre sí en una misma conexión, formando junto con los paneos coreografías que forman distintas combinaciones. El caso más habitual es el travelling out con el desplazamiento del reportero hacia cámara a medida que relata la noticia y un ligero zoom in que sirve para reencuadrar y pasar de un PA a PML o PM. En ocasiones el paseo del periodista dura toda la conexión y en otras se combina con otros tipos de travelling. En cuanto a combinaciones se da el caso del travelling out hasta un punto final de parada desde donde, a posteriori y en otra dirección, el reportero camina hacia atrás y el operador de cámara le sigue en un travelling in. Esta coreografía es la más habitual. A veces se le añade un travelling de seguimiento lateral o uno circular. En otras ocasiones se añade el travelling lateral o circular al travelling out. El travelling circular se usa para pasar del reportero al escenario de la noticia y acabar de nuevo en el reportero con un entrevistado. El paneo es frecuente tras la entradilla del reportero o en cualquier momento de la conexión para mostrar parte de la escena e incluso algún detalle, donde le sucede un zoom in. Existen conexiones en las que solo aparecen panorámicas y otras en las que la panorámica se combina con travelling. Los zoom in se usan a menudo en los travelling in para acercarnos al emisor o entrevistado, o para ver algún detalle. El zoom out permite pasar de un PA a PML o PM.

\section{Gráfico 8. Movimientos de cámara}

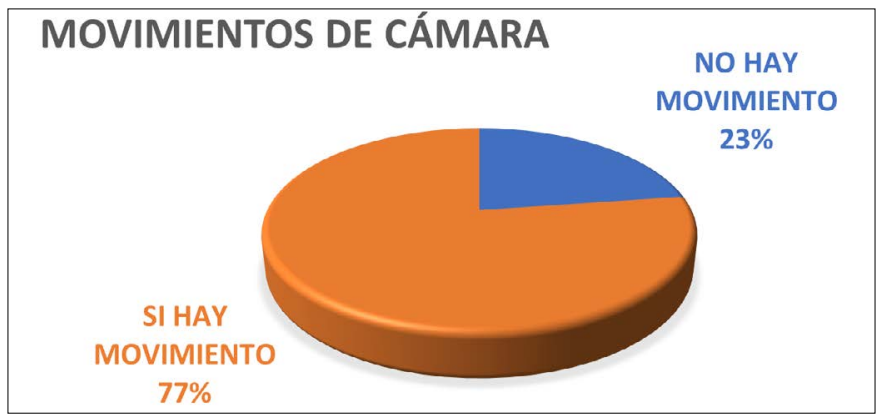

Fuente: elaboración propia

\subsection{Colas durante la conexión}

Las colas en el programa Espejo Público tienen una gran importancia. Su función es ilustrar y es pauta del programa cubrir con colas todo lo posible. Cuando no ocurre es porque el hecho está sucediendo y no hay colas para meter, o porque el hecho es tan importante que debe cubrir lo más posible la pantalla. De hecho, cuando la imagen "es muy buena va a pantalla total con un rótulo que ayude a que el espectador se enganche”, explica Infante (Santana y Sanz, 2021, p. 5).

30 conexiones llevan colas frente a 14. Las colas están desde el principio de la noticia o entran más tarde. Los catch más habituales son a pantalla dividida en dos con la parte izquierda con el reportero y/o entrevistado a $1 / 4$ de la pantalla y colas en los $3 / 4$ de la derecha. Cuando interviene presentadora o colaboradores desde plató se va a pantalla partida al 50\% para pasar en las respuestas al habitual 1/4. La pantalla puede llegar a fraccionarse hasta en 5 partes. Estas divisiones se van alternando a lo largo de los directos. En las conexiones en las que no hay colas están ilustradas con las propias imágenes en directo y tienen mayor movimiento de cámara, 
mayoritariamente panorámicas de relación y de seguimiento. En ocasiones cuando hay entrevista las colas desaparecen cuando se abre plano y entra el reportero para preguntar.

Gráfico 9. Conexiones que incluyen colas

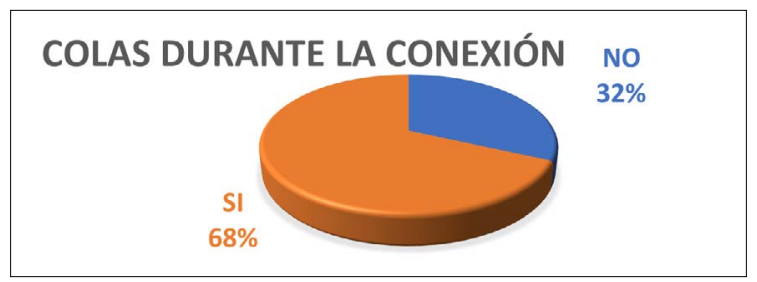

Fuente: elaboración propia

\subsection{Características de las conexiones según su duración}

Las 44 conexiones analizadas han sido divididas según su duración, siendo las más numerosas, las de entre 1 y 2 minutos, con 22 directos. Le siguen las de entre 2 y 3 minutos con 9 directos y después las de más de 3 minutos con 7 directos. El último lugar lo ocupan las de menos de 1 minuto con 6 conexiones en directo.

Gráfico 10. Conexiones en directo según su duración

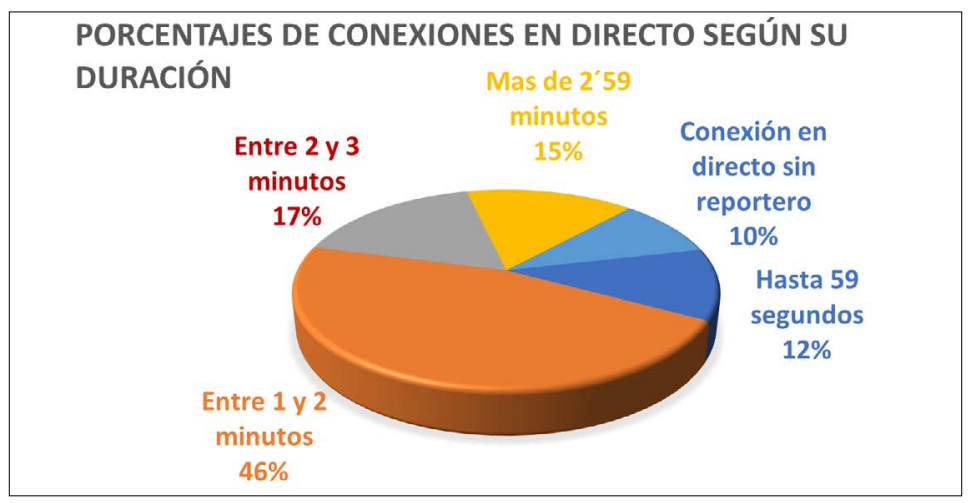

Fuente: elaboración propia

\subsection{Directos de hasta 1 minuto}

De las conexiones en directo inferiores a 1 minuto, la más corta dura 46 segundos y la mayor, 58 segundos. Cabe destacar que 4 de ellas son "última hora" y que todas, según la naturaleza de la acción, poseen un valor informativo directo. En la mitad de ellas el reportero se desplaza y en todas hay movimiento de cámara. Se dan todos los tamaños de plano del análisis. Según la acción del directo hay 3 "sincrónicos", 3 presente que se supone, y 1 directo perpetuo. 


\subsection{Directos de entre 1 y 2 minutos}

El directo de entre 1 y 2 minutos es el más abundante en este estudio, 22. El más corto dura 62 segundos y el más largo 1 minuto y 59 segundos. Solo 6 de ellos son "última hora". En la mayoría de ellos, en 16, no hay desplazamiento del emisor. Según la naturaleza de la acción, todos menos 2, poseen un valor informativo directo. Hay movimiento de cámara en 14 de ellos. Se dan todos los tamaños de plano del análisis. Según la acción del directo hay 9 “directos sincrónicos”, 6 presente que se supone, y 1 directo arbitrario y 5 ilustrativos.

\subsection{Directos de entre 2 y 3 minutos}

El directo de entre 1 y 2 minutos es el segundo más numeroso del estudio. El más corto dura 2 minutos y 6 segundos y el más largo 2 minutos y 46 segundos. "Última hora" son 3. En 7 de ellos, no hay desplazamiento del emisor. Hay movimiento de cámara en 7 de ellos frente a 2 donde no hay. Se dan todos los tamaños de plano del análisis. Según la naturaleza de la acción, todos menos 2 , poseen un valor informativo directo. Según la acción del directo hay 2 “directos sincrónicos”, 3 presente que se supone, y 1 directo perpetuo y 2 ilustrativos.

\subsection{Directos superiores a 3 minutos}

Este apartado requiere especial atención ya que la esencia del directo hace que estos sean de menor duración. En esta sección los directos que superan los tres minutos oscilan desde 3 minutos y 20 segundos hasta 11 minutos y 46 . Hay 2 conexiones de entre 3 y 4 minutos, 3 conexiones de entre 4 y 5 minutos, y 2 de entre 10 y 12 minutos. Lo que justifica tan larga duración son tres características comunes a todos: tienen una entrevista a un protagonista de la noticia que ocupa total o parcialmente la conexión, todos poseen un valor informativo directo, lo que significa que solo puede contarse la noticia y contar con sus testimonios desde el lugar de los hechos; y todos permiten la intervención desde plató. Estas tres características definen los directos de larga duración y la justifican.

En todos estos directos hay colas que lo ilustran y complementan, excepto en el directo de la protesta de los gimnasios y centros deportivos en Cataluña. En este caso las imágenes que necesita ver el espectador son las de la manifestación que está teniendo lugar a tiempo real y por ello no se necesitan colas.

Todos ellos llevan una entrevista a un protagonista de la noticia y conectan con plató desde donde se hacen nuevas preguntas y comentan. En el caso del día 22 de julio en los 3 directos la entrevista es el eje central. En el primero entrevistan a la madre de una niña agredida a las puertas del hospital donde está ingresada ( $\left.9^{\prime} 31^{\prime \prime}\right)$. En el segundo caso entrevistan a un dueño de un gimnasio ante el cierre de estos por rebrotes del Covid en Cataluña, mientras se sucede la manifestación (4’49"). Y en tercer lugar se entrevista a un responsable taurino frente a la protesta que está teniendo lugar en ese mismo momento en las puertas del Ministerio de Trabajo en Madrid (11'46”). El día 22 de julio los directos también llevan entrevista. En el primer directo una reportera entrevista a un cliente del hotel NH donde están confinados los jugadores del equipo de fútbol del equipo Fuenlabrada. En la siguiente de ese día (10') se entrevista a un miembro de una asociación de vecinos de Casa de Campo que denuncia la delincuencia de la zona a causa de los MENAS. El directo superior a 3 minutos del día 23 de julio (4'4"), posee también una entrevista a uno de los comerciantes de Lleida que protestan por el cierre de sus negocios. El día 24 de julio hay 2 conexiones en directo superiores a los 3 minu- 
tos. La primera ( $\left.4^{\prime} 40^{\prime \prime}\right)$ realizada a dos representantes de asociaciones de jóvenes de Mendillori que denuncian ser criminalizados por responsabilizarles del aumento de casos Covid. La segunda (3'35") es un testimonio del Doctor Morales, responsable de las plantas de Covid del Hospital Arnau de Villanova en Lleida.

Estas conexiones en directo no llevan desplazamiento del emisor cuando la entrevista dura toda la conexión. Sí lleva desplazamiento cuando el reportero recorre la escena antes de ir al encuentro del entrevistado. Solo en esos casos hay travelling de seguimiento, in, out y circulares. En todas sí hay paneos a izquierda y a derecha para reencuadrar en la respuesta o nueva pregunta.

A pesar de que la naturaleza de la acción objeto del directo es de valor informativo directo: "asistimos a algo que está ocurriendo en ese momento", la categoría del directo según el escenario varía. Solo son 3 los "directos sincrónicos" en los que la acción está ocurriendo y cubre todo el contenido informativo. El resto son 3 directos que son: un presente que se supone, imagina, y 2 directos ilustrativos.

Tabla 1. Resultados del análisis diario de las conexiones en directo

\begin{tabular}{|c|c|c|c|c|c|c|c|c|c|c|c|c|c|c|}
\hline & & & & & & & & \multicolumn{7}{|c|}{ ANÁLISIS DE LA IMAGEN } \\
\hline \multirow{8}{*}{$<59^{*}$} & $\mathbf{P}$ & DURACIÓN & $\mathbf{L}$ & TE & UH & EN & DE & TP & MC & $\mathbf{S}$ & IL & NDA & CSEA & $\mathbf{C L}$ \\
\hline & \multirow{2}{*}{20} & N1. CD1. $48 *$ & $\mathrm{E}$ & $\mathrm{R}$ & SI & NO & NO & PML & Sí & $\mathrm{D}$ & $\mathrm{N}$ & VID & PQS & SI \\
\hline & & N13. CD7. $46^{*}$ & $\mathrm{E}$ & $\mathrm{R}$ & NO & NO & SI & $\mathrm{PA}$ & SI & $\mathrm{D}$ & $\mathrm{N}$ & VID & PQS & NO \\
\hline & 21 & N2. CD2. 58“" & $\mathrm{E}$ & $\mathrm{R}$ & SI & NO & NO & $\mathrm{PM}$ & SI & $\mathrm{D}$ & $\mathrm{N}$ & VID & SIN & NO \\
\hline & 22 & NINGUNO & & & & & & & & & & & & \\
\hline & \multirow{2}{*}{23} & N3. CD3. $55^{\circ}$ & $\mathrm{E}$ & $\mathrm{R}$ & SI & NO & NO & PG & SI & $\mathrm{D}$ & $\mathrm{N}$ & VID & PQS & SI \\
\hline & & N6. CD3. 57" & $\mathrm{E}$ & $\mathrm{R}$ & NO & NO & SI & $\mathrm{PA}$ & SI & $\mathrm{D}$ & $\mathrm{N}$ & VID & SIN & NO \\
\hline & 24 & N2. CD2. 53" & $\mathrm{E}$ & $\mathrm{R}$ & SI & NO & SI & $\mathrm{PM}$ & SI & $\mathrm{D}$ & $\mathrm{N}$ & VID & SIN & NO \\
\hline \multirow{14}{*}{$1-2^{\prime}$} & $\mathbf{P}$ & DURACIÓN & $\mathbf{L}$ & TE & UH & EN & DE & TP & MC & $\mathbf{S}$ & IL & NDA & CSEA & CL \\
\hline & \multirow{5}{*}{20} & N2. CD2. 1.02' & $\mathrm{E}$ & $\mathrm{R}$ & NO & NO & SI & PML & SI & $\mathrm{D}$ & $\mathrm{N}$ & VID & ARB & SI \\
\hline & & N3. CD3. $1,07^{\prime}$ & $\mathrm{E}$ & $\mathrm{R}$ & NO & SI & SI & PML & SI & $\mathrm{D}$ & $\mathrm{N}$ & VID & SIN & SI \\
\hline & & N10. CD5. $1,18^{\prime}$ & $\mathrm{E}$ & $\mathrm{R}$ & NO & NO & SI & PML & SI & $\mathrm{D}$ & $\mathrm{N}$ & VID & CON & NO \\
\hline & & N11. CD6. $1,56^{\prime}$ & $\mathrm{E}$ & $\mathrm{R}$ & SI & SI & NO & PG & SI & $\mathrm{D}$ & $\mathrm{N}$ & VID & SIN & NO \\
\hline & & N18. CD8. $1,19^{\prime}$ & $\mathrm{E}$ & $\mathrm{R}$ & NO & NO & NO & $\mathrm{PM}$ & NO & $\mathrm{D}$ & $\mathrm{N}$ & VII & ILU & SI \\
\hline & \multirow{5}{*}{21} & N1. CD1. 1,12' & $\mathrm{E}$ & $\mathrm{R}$ & NO & NO & NO & PML & SI & $\mathrm{D}$ & $\mathrm{N}$ & VID & SIN & SI \\
\hline & & N4. CD4. $1,29^{\prime}$ & $E$ & $\mathrm{R}$ & SI & NO & NO & $\mathrm{PM}$ & NO & $\mathrm{D}$ & $\mathrm{N}$ & VII & ILU & SI \\
\hline & & N7. CD5. $1,48^{\prime}$ & $\mathrm{E}$ & $\mathrm{R}$ & SI & NO & NO & $\mathrm{PA}$ & SI & $\mathrm{D}$ & $\mathrm{N}$ & VID & SIN & NO \\
\hline & & N14. CD8. $1,02^{\prime}$ & $\mathrm{E}$ & $\mathrm{R}$ & NO & NO & NO & $\mathrm{PA}$ & SI & $\mathrm{D}$ & $\mathrm{N}$ & VID & ILU & SI \\
\hline & & N23. CD12. $1,45^{\prime}$ & $\mathrm{E} / \mathrm{I}$ & $\mathrm{R}$ & NO & SI & SI & $\mathrm{PA}$ & SI & $\mathrm{D}$ & $\mathrm{N}$ & VID & SIN & NO \\
\hline & \multirow{3}{*}{22} & N1. CD1. 1,08' & $E$ & $\mathrm{R}$ & NO & SI & NO & PML & NO & $\mathrm{D}$ & $\mathrm{N}$ & VID & PQS & SI \\
\hline & & N11. CD5. $1,22^{\prime}$ & $\mathrm{E}$ & $\mathrm{R}$ & SI & NO & NO & PML & NO & $\mathrm{D}$ & $\mathrm{N}$ & VID & PQS & SI \\
\hline & & N19. CD7. 1,58' & $\mathrm{E}$ & $\mathrm{R}$ & NO & SI & NO & PA & SI & $\mathrm{D}$ & $\mathrm{N}$ & VID & SIN & NO \\
\hline
\end{tabular}




\begin{tabular}{|c|c|c|c|c|c|c|c|c|c|c|c|c|c|c|}
\hline & \multirow{6}{*}{23} & N1. CD1. 1,43' & $\mathrm{E}$ & $\mathrm{R}$ & SI & NO & NO & PML & NO & $\mathrm{D}$ & $\mathrm{N}$ & VID & PQS & SI \\
\hline & & N3. CD2. $1,16^{\prime}$ & $\mathrm{E}$ & $\mathrm{R}$ & SI & NO & NO & PML & SI & $\mathrm{D}$ & $\mathrm{N}$ & VID & PQS & SI \\
\hline & & N10 CD4. $1,14^{\prime}$ & $\mathrm{E}$ & $\mathrm{R}$ & NO & SI & NO & $\mathrm{PA}$ & SI & $\mathrm{D}$ & $\mathrm{N}$ & VII & ILU & SI \\
\hline & & N12. CD5. $1,49^{\prime}$ & $\mathrm{E}$ & $\mathrm{R}$ & NO & SI & NO & $\mathrm{PA}$ & SI & $\mathrm{D}$ & $\mathrm{N}$ & VID & ILU & SI \\
\hline & & N13. CD6. $1,59^{\prime}$ & $\mathrm{E}$ & $\mathrm{R}$ & NO & SI & NO & PML & SI & $\mathrm{D}$ & $\mathrm{N}$ & VID & SIN & SI \\
\hline & & N15. CD8. $1,04^{\prime}$ & $\mathrm{E}$ & $\mathrm{R}$ & NO & NO & NO & $\mathrm{PA}$ & NO & $\mathrm{D}$ & $\mathrm{N}$ & VID & PQS & SI \\
\hline & \multirow{3}{*}{24} & N1. CD1. $1,07^{\prime}$ & E & $\mathrm{R}$ & NO & NO & SI & $\mathrm{PA}$ & SI & $\mathrm{D}$ & $\mathrm{N}$ & VID & SIN & NO \\
\hline & & N7. CD3. $1,53^{\prime}$ & $\mathrm{E}$ & $\mathrm{R}$ & NO & NO & SI & $\mathrm{PA}$ & SI & $\mathrm{D}$ & $\mathrm{N}$ & VID & SIN & NO \\
\hline & & N21. CD10. 1,15' & $\mathrm{E}$ & $\mathrm{R}$ & NO & NO & NO & PM & NO & $\mathrm{D}$ & $\mathrm{N}$ & VID & PQS & SI \\
\hline \multirow{10}{*}{$2-3^{\prime}$} & $\mathbf{P}$ & DURACIÓN & $\mathbf{L}$ & TE & UH & EN & DE & TP & MC & $\mathbf{S}$ & IL & NDA & CSEA & CL \\
\hline & 20 & N8. CD4. $2,06^{\prime}$ & $\mathrm{E}$ & $\mathrm{R}$ & NO & $\mathrm{NO}$ & NO & $\mathrm{PM}$ & NO & $\mathrm{D}$ & $\mathrm{N}$ & VII & PER & SI \\
\hline & \multirow{2}{*}{21} & N11. CD6. 2,22' & $\mathrm{E}$ & $\mathrm{R}$ & SI & NO & NO & $\mathrm{PM}$ & SI & $\mathrm{D}$ & $\mathrm{N}$ & VID & PQS & SI \\
\hline & & N13. CD7. 2,08' & $\mathrm{E}$ & $\mathrm{R}$ & NO & SI & NO & $\mathrm{PA}$ & SI & $\mathrm{D}$ & $\mathrm{N}$ & VID & PQS & SI \\
\hline & 22 & N2. CD2. $2,15^{\prime}$ & $\mathrm{E}$ & $\mathrm{R}$ & SI & SI & NO & $\mathrm{PM}$ & SI & $\mathrm{D}$ & $\mathrm{N}$ & VID & PQS & SI \\
\hline & 23 & N18. CD10. $2,41^{\prime}$ & $\mathrm{E}$ & $\mathrm{R}$ & NO & SI & NO & PML & SI & $\mathrm{D}$ & $\mathrm{N}$ & VID & SIN & SI \\
\hline & \multirow{4}{*}{24} & N8 CD4. $2,21^{\prime}$ & $\mathrm{E}$ & $\mathrm{R}$ & NO & SI & SI & $\mathrm{PA}$ & SI & $\mathrm{D}$ & $\mathrm{N}$ & VID & SIN & SI \\
\hline & & N16. CD7. 2,11' & $\mathrm{E}$ & $\mathrm{R}$ & NO & SI & NO & $\mathrm{PM}$ & SI & $\mathrm{D}$ & $\mathrm{N}$ & VII & ILU & NO \\
\hline & & N19. CD8. $1,59^{\prime}$ & $\mathrm{E}$ & $\mathrm{R}$ & SI & NO & NO & PM & NO & $\mathrm{D}$ & $\mathrm{N}$ & VID & SIN & SI \\
\hline & & N24. CD12. $2,22^{\prime}$ & $\mathrm{E}$ & $\mathrm{R}$ & NO & SI & SI & PG & SI & $\mathrm{D}$ & $\mathrm{N}$ & VID & ILU & SI \\
\hline \multirow{9}{*}{$>\mathbf{3}^{\prime}$} & $\mathbf{P}$ & DURACIÓN & $\mathbf{L}$ & TE & UH & EN & DE & TP & MC & $\mathbf{S}$ & IL & NDA & CSEA & CL \\
\hline & 20 & NINGUNO & & & & & & & & & & & & \\
\hline & \multirow{2}{*}{21} & N17. CD9. $4,49^{\prime}$ & $\mathrm{E}$ & $\mathrm{R}$ & SI & SI & SI & $\mathrm{PM}$ & SI & $\mathrm{D}$ & $\mathrm{N}$ & VID & SIN & NO \\
\hline & & N18. CD10. $11,46^{\prime}$ & $\mathrm{E}$ & $\mathrm{R}$ & SI & SI & SI & $\mathrm{PA}$ & SI & $\mathrm{D}$ & $\mathrm{N}$ & VID & SIN & NO \\
\hline & \multirow{2}{*}{22} & N10. CD4. $3,20^{\prime}$ & $\mathrm{E}$ & $\mathrm{R}$ & SI & SI & NO & PML & SI & $\mathrm{D}$ & $\mathrm{N}$ & VID & SIN & SI \\
\hline & & N16 CD6. 10' & $\mathrm{E}$ & $\mathrm{R}$ & SI & SI & NO & $\mathrm{PA}$ & SI & $\mathrm{D}$ & $\mathrm{N}$ & VID & PQS & SI \\
\hline & 23 & N14. CD7. 4,04' & $\mathrm{E}$ & $\mathrm{R}$ & NO & SI & SI & $\mathrm{PM}$ & SI & $\mathrm{D}$ & $\mathrm{N}$ & VID & PQS & SI \\
\hline & \multirow{2}{*}{24} & N20. CD9. $4,15^{\prime}$ & $\mathrm{E}$ & $\mathrm{R}$ & NO & SI & NO & $\mathrm{PA}$ & SI & $\mathrm{D}$ & $\mathrm{N}$ & VID & ILU & SI \\
\hline & & N23. CD11. $3,35^{\prime}$ & $\mathrm{E}$ & $\mathrm{R}$ & SI & SI & NO & PM & SI & $\mathrm{D}$ & $\mathrm{N}$ & VID & PQS & SI \\
\hline
\end{tabular}

Fuente: elaboración propia 
Tabla 2. Leyenda de la tabla

\section{LEYENDA:}

P: PROGRAMA

N.CD: No NOTICIA Y No CONEXIÓN EN DIRECTO

L: LOCALIZACIÓN

TE: TIPOLOGÍA DEL EMISOR

UH: ÚLTIMA HORA

EN: ENTREVISTA

DE: DESPLAZAMIENTO DEL EMISOR

TP: TIPO DE PLANO

MC: MOVIMIENTO DE CÁMARA

S: SONIDO

IL: ILUMINACIÓN

NDA: NATURALEZA DE LA ACCIÓN

CSEA: CATEGORÍA SEGÚN ESCENARIO DE LA ACCIÓN

CL: COLAS

E/I: EXTERIOR/INTERIOR
R: REPORTERO/A

PG: PLANO GENERAL

PA: PLANO AMERICANO

PML: PLANO MEDIO LARGO

PM: PLANO MEDIO

D: DIRECTO

$\mathrm{N}$ : NATURAL

VID: VALOR INFORMATIVO DIRECTO

VII: VALOR INFORMATIVO INDIRECTO

SIN: SINCRÓNICO

PQS: PRESENTE QUE SE SUPONE

ILU: ILUSTRATIVO

PER: PERPETUO

CON: CONTRARIO

ARB: ARBITRARIO

Fuente: elaboración propia

\section{Conclusiones}

El uso de la tecnología de envío de imagen por señal móvil es más operativo que el uso del DSNG.

Los directos del magacín Espejo Público cumplen mayoritariamente las pautas del directo en contenido que marca la dirección del programa: transmitir actualidad, contar bien la historia y desde todos los puntos de vista, hablar con el protagonista de la noticia y alertarle de ser concreto; y en lenguaje audiovisual: "que se mueva el reportero, tratar de localizarse en exterior, que se vea dónde está, dar el cuadro más completo que se pueda, que dé mayor movimiento y que explique mejor la historia” (Santana y Sanz, 2021, p. 3).

Los directos cuya naturaleza de la acción tiene un valor informativo directo suponen la mayoría de las conexiones, un 89\%.

En la categoría que analiza el escenario donde tiene lugar la acción del directo, el más usado, en un 43\%, es el "directo sincrónico", en el que la acción ocurre en el momento mismo de la captación y emisión de la noticia y dura todo el tiempo de ésta. Le siguen el 
presente que se supone, en el que algo está pasando, pero no lo podemos ver, en un 33\%; el directo ilustrativo en el que la acción ya pasó, pero el lugar sigue siendo significativo, en un 19\%; el perpetuo donde la relación con el lugar es invariable, en un 5\%; y el contrario, que habla de acciones ocurridas en otros lugares, en un $2 \%$.

La combinación de un valor informativo directo y un "directo sincrónico" es el directo por excelencia, el más puro directo. La combinación de un valor informativo indirecto, y un directo arbitrario, supone el directo con menos valor.

De los directos analizados hay un alto porcentaje de conexiones de "última hora", un 41\% y todas poseen un valor informativo directo según la naturaleza de la acción, excepto una. Estos se caracterizan por mantener la esencia primigenia del directo retransmitiendo desde el mismo lugar de los hechos. A pesar de contar con un valor informativo directo, la categoría del directo según el escenario de la acción es variada.

La entrevista en el directo es un sello distintivo de actualidad y ofrece el testimonio de algún protagonista de la noticia. Su dinámica de grabación favorece el protagonismo del testimonio y no el del reportero. Para ello el cámara ocupa el lugar del reportero que queda en escorzo o desaparece de cuadro. Ante sus preguntas no siempre es reencuadrado, pudiendo quedar su pregunta en off. Al finalizar la entrevista se suele reencuadrar al reportero para su salidilla, sacando de cuadro al entrevistado.

La espectacularidad del directo viene marcada más por el movimiento de cámara que por el desplazamiento del emisor. El desplazamiento del reportero -32\% - es menos significativo que el movimiento de cámara en el directo -77\%-. El desplazamiento del reportero durante las conexiones incide en la tesis de Infante (2020, p. 1) en la que el directo ha de mostrar que se está en la calle y no solo en plató. Además, estos desplazamientos suplen la ausencia de acción.

En los directos se dan todos los tipos de plano, aunque el plano mayoritario es el Plano Medio en su versión normal y larga. Este supone un 57\% de la totalidad. Le sigue el Plano Americano, en un 36\% y el Plano General, en un 7\%. Se podría decir que también se da el Plano Secuencia en una ocasión.

Es el movimiento dentro de la noticia y la combinación de travelling y panorámicas lo que da sensación de espectacularidad. Las conexiones en directo con movimiento de cámara son mayoritarias, se dan en un $77 \%$. Se dan todos los movimientos posibles: travelling: out, in, circular y de seguimiento lateral; panorámicas o paneos: a izquierda y derecha, arriba y abajo; y los movimientos ópticos: zoom in y zoom out.

De los 44 directos analizados el movimiento que aparece mayoritariamente es el travelling. El travelling mayoritario es el travelling out, aparece en 24 conexiones. El travelling in en 8, el travelling lateral de seguimiento en 7, y el circular en 2 . En cuanto a paneos, a derecha e izquierda aparecen en 27 conexiones, mientras que paneos arriba y abajo, en 4 . El zoom in aparece en 9 conexiones y zoom out en 10. Es habitual la combinación de estos movimientos. El caso más común es el travelling out con desplazamiento de reportero a cámara y ligero zoom in para pasar de un PA a PML o PM. El travelling out seguido de travelling in con reportero caminando hacia atrás es habitual. A veces se le añade un travelling de seguimiento lateral o uno circular al in y al out. El travelling circular se usa para pasar del reportero al escenario y acabar de nuevo en el reportero con un entrevistado. El paneo siempre muestra parte relevante de la escena. Los zoom alejan y acercan al emisor o entrevistado o muestran algún detalle de algún elemento de la noticia o pasan de PA a PML o PM. 
Un 68\% de las conexiones en directo de Espejo Público llevan colas que ilustran la noticia. Cuando no aparecen es, bien porque no hay colas para meter o porque el hecho es tan importante que debe cubrir lo más posible la pantalla. Pueden estar desde el principio de la noticia o bien entrar más tarde. En las conexiones en las que no hay colas están ilustradas con las propias imágenes en directo y tienen mayor movimiento de cámara. En estos casos abundan las panorámicas de relación y de seguimiento. El catch más habitual es el de pantalla dividida en dos con la parte izquierda con el reportero y/o entrevistado a 1/4 de la pantalla y colas en los $3 / 4$ de la derecha, o al 50\% cuando interviene la presentadora o colaboradores desde plató. Los directos que son "sincrónicos" y la noticia está pasando en ese momento habitualmente no llevan colas porque la actividad de la acción es recogida en el momento mismo de la captación de la noticia.

El reportero de Informativos es un redactor-informador, mientras que el reportero del magacín es un redactor-narrador que buscar el testimonio, lo que está pasando y lo trae al espectador. "Para contar esas historias la mochila se hace imprescindible" concluye Donate (Santana y Sanz, 2021, p. 7).

Las conexiones más habituales en Espejo Público son las de entre 1 y 2 minutos, un $46 \%$ del total. Le siguen las de entre 2 y 3 minutos con un $17 \%$ e inmediatamente después las de más de 3 minutos con $15 \%$ y en último lugar las de menos de 1 minuto con un $12 \%$.

Los directos de más de tres minutos tienen tres características comunes que los justifican: llevan entrevista a un protagonista de la noticia total o parcial, se interviene desde plató y poseen un valor informativo directo. Estas conexiones en directo no llevan desplazamiento del emisor cuando la entrevista dura toda la conexión.

El futuro de la televisión generalista está en ofrecer la noticia en directo en el formato que sea. Estar en la calle, contar desde allí, y menos plató, será el futuro de los programas informativos, además de ganar el pulso a la desinformación y las fake news. Información contrastada y en la calle es lo que demanda el espectador, según Donate (Santana y Sanz, 2021, p. 6).

\section{Agradecimientos}

Este artículo ha sido traducido al inglés por Gorka Hodson.

\section{Referencias bibliográficas}

Barroso, J. (1996). Realización de los géneros televisivos. Madrid. Síntesis.

Cebrián Herreros, M. (1978) Introducción al lenguaje de la televisión. Madrid. Pirámide.

Cebrián Herreros, M. (1992). Géneros informativos audiovisuales. Madrid. Ciencia 3 Distribución S.A.

De Lara, A., Arias, F., Carvajal, M., \& García, J. A. (2015). Ranking de innovación periodística 2014 en España. Selección y análisis de 25 iniciativas. El Profesional de la Información, 24 (3), 235-245. 10.3145/epi.2015.may.02

De Miguel, R. (2015). La observación sistemática y participante. En: María Rosa Berganza \& Luis San Román, Investigar en comunicación (277-293). Madrid. McGraw-Hill. 
García-Avilés, J. A., Carvajal, M. \& Comín, M.(2016). Cómo innovar en periodismo. Entrevistas a 27 profesionales. Diego Marín. Obtenido de: https://www.researchgate.net/publication/312187586_Como_innovar_en_Periodismo_Entrevistas_a_27_profesionales González Requena, J. (1988). El discurso televisivo: espectáculo de la posmodernidad. Madrid. Cátedra.

LiveU (2020). Sitio. https://www.liveu.tv/liveu-news/press-releases/291-2020/cartier-queen-s-cup-2020-polo-tournament-isthe-first-multi-camera-sports-production-using-liveu\%E2\%80\%99s-lu800

Lozano Rendón, J. (2004). Espectacularización de la información en noticieros televisivos de Canadá, Estados Unidos y México. Diálogo Político. 21 (1), 101-116.

Marín, C. Periodismo audiovisual: información, entretenimiento y tecnologías multimedia. Gedisa. Sitio. https://elibro.net/en/ ereader/nebrija/61119?page $=91$

Mateos, C. (2013). El directo ético y el directo patético en los informativos de televisión. El Estado del Periodismo: Desafíos en el Siglo de la Comunicación. Comunicación y Medios (n. 28), 61-79. ISSN 0719-152. Obtenido de: https://enfoqueseducacionales.uchile. cl/index.php/RCM/article/view/29700/32118

Maniewicz, M. (2-2019). Integración de las comunicaciones por satélite en el ecosistema 5G. ITUNewsMAGAZINE. (núm.2) 4-7. Obtenido de: https://www.itu.int/en/itunews/Documents/2019/2019-02/2019_ITUNews02-es.pdf

Mayoral, J; Sapag, P; Huerta, A \& Díez F. J. (2008). Redacción periodística en televisión. Madrid. Síntesis.

Millerson, G. (1991). Técnicas de realización y producción en televisión. Madrid. IORTV.

Premios Ondas (2019). Obtenido de: https://www.premiosondas.com/historia_2019-2010-10.php

Premio Iris al mejor programa de actualidad en 2014 (Antena 3, 2020). Obtenido de: https://www.antena3.com/objetivotv/actualidad/espana/espejo-publico-recoge-premio-iris-mejor-programa-actualidad_20140611578fbda54beb2898948f7dcc.html

Santana, S. y Sanz, V. (15 de octubre de 2021). Entrevista a Nuria Donate, productora de Espejo Público realizada por Saida Santana Mahmut y Vicente Sanz de León, 15 noviembre 2020. Saidasantanacreaciones. https://tinyurl.com/4ezwbj3v

Santana, S. y Sanz, V. (15 de octubre de 2021). Entrevista a Araceli Infante Castellanos, directora de Espejo Público realizada por Saida Santana Mahmut y Vicente Sanz de León, 15 noviembre 2020. Saidasantanacreaciones. https://tinyurl.com/4rmcakxa 
